\title{
Sabor da, na e para Geografia*
}

Lúcia Helena Batista Gratão

Eduardo Marandola Júnior ***

\section{Resumo}

Pensar a relação geografia e sabor implica a compreensão da existência experiencial e cultural humana, expressa pela geograficidade: expressão e significado do envolvimento homemmeio. Buscamos refletir sobre as consequências e as implicações de uma geografia do sabor, a partir de um entendimento epistemológico que permita pensar não apenas o sabor enquanto tema de estudo geográfico (sabor na geografia), mas sobretudo o sabor como fenômeno, constituindo também a essência da experiência geográfica (sabor para a geografia).

Palavras-chave: Paisagem e lugar; Imaginário; Experiência; Geografia humanista e cultural; Epistemologia da Geografia.

Savor of, in and for Geography

\section{Abstract}

Geography and savor relationship evolves comprehension of experiential and cultural existence, expressed by geographicity:

* Uma primeira versão deste texto foi apresentada no Encontro Nacional da Associação Nacional de Pós-Graduação e Pesquisa em Geografia (ANPEGE), realizado em Curitiba de 28/09 à 02/10 de 2009.

** Departamento de Geociências, Universidade Estadual de Londrina (lugratao@uel.br).

*** Núcleo de Estudos de População, Universidade Estadual de Campinas (eduardom@nepo.unicamp.br).

Geosul, Florianópolis, v. 26, n. 51, p 59-74, jan./jun. 2011 
GRATÃO, L.H.B \& MARANDOLA JR., E. Sabor da, na e para Geografia

man-environment meaning. This paper reflects about savor geography consequences, from epistemological understanding that permits think savor as geographic theme (savor in Geography), as savor like phenomenon, it constitutes essence of the geographic experience (savor to geography).

Key words: Landscape and place; Imaginary; Experience; Humanist and cultural Geography; Epistemology of Geography.

\section{Introdução}

Sabor é um dos sentidos que, tanto quanto os demais, media a experiência ambiental, fundando, a partir do corpo uma geograficidade: expressão e significado do envolvimento homemmeio (DARDEL, 1952). A tradição de estudos perceptivos e culturais em Geografia, apesar da ênfase na experiência, mantémse atrelada de certa maneira à tradição visual moderna, dando maior ênfase à visão, deixando em segundo plano os demais sentidos. No entanto, não percebemos o ambiente apenas pela visão ou pela audição; todos os sentidos mediam a nossa experiência espacial, tendo eles significados culturais específicos. A experiência ambiental é um fenômeno completo mediado pelo corpo via sentidos (MERLEAU-PONTY, 1971).

Uma geografia que se pretende humanista e cultural necessita, para pensar o espaço e o significado da experiência humana sobre a terra (CLAVAL, 2001), incorporar o paladar a seus temas de interesse. Para isso, é fundamental ir além da degustação, da alimentação e da gastronomia. O paladar se manifesta enquanto fenômeno da experiência geográfica a partir do sabor. Ligado ao gosto, à experiência, à memória e aos valores culturalmente construídos, o sabor nos permite incorporar as dimensões da experiência e da cultura da geograficidade.

Neste texto, buscamos reunir elementos teóricometodológicos para pensar a relação geografia e sabor, composta a 
GRATÃO, L.H.B \& MARANDOLA JR., E. Sabor da, na e para Geografia

partir do entendimento fenomenológico da experiência pautada na existência e da intersubjetividade inerente à vivência cultural (RELPH, 1979; MARANDOLA JR., 2005). Paisagem, lugar, identidade e imaginário são os fenômenos reveladores desta geograficidade, reclamando um entendimento epistemológico que permita pensar não apenas o sabor enquanto tema de estudo geográfico (sabor na geografia), mas, sobretudo o sabor como fenômeno, constituindo também a essência da experiência geográfica.

Em vista disso, o texto reflete sobre o sabor da geografia, enquanto componente essencial da experiência geográfica, o sabor na geografia, contextualizando a preocupação com o tema nos estudos humanistas e culturais, e o sabor para a geografia, projetando as potencialidades do estudo do sabor para o pensamento geográfico.

\section{Sabor da Geografia}

Sabor vem de saborear. Saborear é uma palavra que brota e se estende do sentido do gosto, do paladar. Uma experiência com o mundo mediada pelo tato (sabor é tátil, palativo) no ato de comer. Uma experiência mediada pela boca (contato direto) e não apenas pelos olhos. Sabor na geografia faz parte da experiência da paisagem que é gosto e sensações, além de cor, som e cheiro (GRATÃO, 2009a).

Os sentidos, enquanto corporeidade que mediam nossas relações com a natureza ou o meio que habitamos, são essenciais para a construção das ideias e do conhecimento humano (MERLEAU-PONTY, 1971). E o paladar não é diferente. Por esta mediação, o imaginário da natureza e a vivência dos lugares procura recuperar ou recriar a identidade cultural pelos valores tradicionais: da terra à degustação dos seus frutos (GRATÃO, 2009b).

Como o sabor se insere, manifesta ou se projeta na sustentação de uma cultura? O sabor está "enraizado" na 
GRATÃO, L.H.B \& MARANDOLA JR., E. Sabor da, na e para Geografia

geograficidade, ligação essencial, telúrica, homem-Terra. É assim que o enveredar-se por esse campo da Geografia parte de um fazer enraizado na valoração da paisagem e da cultura. O sabor que brota da terra, que envolve valores culturais, éticos e humanos, numa relação que ultrapassa o inventário dos conteúdos da área e de seus objetos. Uma relação que se estabelece no modo de ver o mundo, aos seus padrões objetivos, mas também às crenças das pessoas, aos significados subjetivos dos lugares.

O sabor brota da imaginação enquanto mediadora da experiência humana, à maneira de Bachelard (1993). Uma extensão do corpo que media a relação homem-paisagem. Portanto, uma projeção cultural, uma paisagem valorizada (MACHADO, 1996; BLEY, 1996).

Por este sentido, a paisagem é vivida a partir de um atributo invisível de sensação. Estamos falando de uma paisagem sentida, experimentada, provada, saboreada, a qual permite estabelecer sua essência. É por esta qualidade de essência que se diz 'que quanto mais modos terá de ver a paisagem, mais próximos estaremos da descrição da essência do fenômeno'. Mais essencialmente, o sabor encontra-se na procura desta essência da paisagem. A paisagem vai além de um modo de ver o mundo. Mais, ela se manifesta também enquanto imaginário da natureza. A paisagem, tal como vista fenomenologicamente por Besse (2006), é proximidade e envolvimento: é a forma própria do homem pensar e sentir o mundo.

O sabor expresso no gosto e no cheiro é imaginação; é memória, pois estes nos remetem a outros lugares, a sentimentos agradáveis (ou desagradáveis), a experiências vividas. Desta maneira experienciamos o mundo com o nosso corpo de sentidos nossa corporeidade. Os sentidos são extensões desse corpo o qual é a própria geografia sensória que se desenha a partir de uma dada corporeidade, fundamento da experiência do mundo.

Sabor é experiencial e a experiência é constituída de sentimento e pensamento (TUAN, 1983). Como o sentimento humano não é uma sucessão de sensações distintas, a memória e a 
GRATÃO, L.H.B \& MARANDOLA JR., E. Sabor da, na e para Geografia intuição são capazes de produzir impactos sensoriais no cambiante fluxo da experiência, de modo que poderíamos falar de uma vida do sentimento como falamos de uma vida do pensamento. Tuan afirma que ambos estão muito próximos das extremidades de um continuum experiencial, sendo ambos maneiras de conhecer:

Os sentidos do olfato e do tato são educados mentalmente? Tendemos a negligenciar o poder cognitivo desses sentidos. No entanto, o verbo francês savoir ('saber') está intimamente relacionado com o inglês savor. O paladar, o olfato $\mathrm{e} o$ tato podem atingir um extraordinário refinamento. Eles discriminam em meio à riqueza de sensações e articulam os mundos gustativo, olfativo e textural (TUAN, 1983, p.11).

A experiência é integral, e por isso não podemos excluir os sabores como menos importantes. Os sabores também são espaciais, pois constituem e descrevem lugares e paisagens. $\mathrm{O}$ sabor é corporificado não apenas na alusão, mas sobretudo na concretude da experiência geográfica. Quem não se lembra da casa da avó a partir do sabor de seu prato especial, ou de uma viagem inesquecível lembrada pelos sabores experimentados? A memória, ela própria, é espacial, associada aos lugares, e não ao tempo (BACHELARD, 1993). E os alguns lugares vêm a nós pelo sabor.

De outro lado, até mesmo as formas espaciais são percebidas e constituídas pelos sabores, como mostra Tuan (1983, p.13):

É possível argumentar que o paladar, o odor e mesmo a audição não nos dão, por si mesmos, a sensação de espaço. A questão é muito acadêmica, porque, a maioria das pessoas faz uso dos cinco sentidos, que se reforçam mútua e constantemente para fornecer o mundo em que vivemos, intrincadamente ordenado e carregado de emoções. O paladar, por exemplo, envolve quase invariavelmente o tato e o olfato: a língua rola ao redor da bala, explorando sua forma enquanto o olfato registra o aroma de caramelo (TUAN, 1983, p.13). 
GRATÃO, L.H.B \& MARANDOLA JR., E. Sabor da, na e para Geografia

$\mathrm{O}$ espaço pode ser experienciado de várias maneiras. $\mathrm{O}$ paladar, o olfato, a sensibilidade da pele e a audição não podem individualmente (nem sequer talvez juntos) nos tornar cientes de um mundo exterior habitado por objetos. No entanto, conforme Tuan (1983, p.14), em combinação com as faculdades "espacializantes" da visão e do tato, esses sentidos essencialmente não distanciadores enriquecem muito nossa apreensão do caráter espacial e geométrico do mundo.

Podemos pensar que alguns sentidos nos permitem realizar relações topológicas de distância, proximidade e ordenação, classicamente entendidas como geográficas. Nos acostumamos no Ocidente a utilizar a visão e o tato para isso. Por outro lado, os outros sentidos (paladar, audição e olfato) nos permitem adensar o sentido dos lugares e paisagens, aprofundando e qualificando a experiência e o seu significado geográfico.

Em inglês, por exemplo, Tuan lembra que se qualificam alguns sabores como sharp ("picante"), e outros como flat ("insípido"). O significado destes termos é realçado pelo uso metafórico no reino do paladar, os quais são utilizados também para se referir a lugares e paisagens.

Da experiência espacial existencialmente significada, o sabor da geografia se estende aos grupos culturais, conformando na paisagem uma forma própria de habitar o mundo. Enquanto expressão da identidade cultural, o sabor é um sentido essencial para se compreender as tradições culturais, sendo um caminho que leva à conservação e preservação do ambiente (GRATÃO, 2009b). Deve-se levar em conta o papel ativo do homem na transformação do meio, produzindo inclusive a sua comida sem depender exclusivamente dos recursos do ambiente natural imediato (MONTANARI, 2009). A alimentação é assim tanto extensão dos produtos da terra quanto, e especialmente, memória da natureza.

Claude Lévi-Strauss foi pioneiro em mostrar esta relação cultural entre a alimentação, as formas de preparo seus significados. Em $O$ cru e o cozido o antropólogo toma o cozinhar como processo de transformação da natureza em cultura, tornando 
GRATÃO, L.H.B \& MARANDOLA JR., E. Sabor da, na e para Geografia

aquilo que é natural em cultural por meio do domínio ou conquista do fogo (LÉVI-STRAUSS, 2004).

Não é por nada que cozinhar foi uma das primeiras expressões ligadas à formação cultural das sociedades (MONTANARI, 2009). Entre as muitas atividades que os homens desenvolvem, cozinhar (transformar os produtos naturais em algo diferente, que depois é comido) é exclusivo da espécie humana. Se se investe numa cultura da comida - elaborações gastronômicas numa perspectiva de não perder os saberes da comida, está aqui o sabor da Geografia. Preservar os gostos significa preservar o sabor, implicando também a preservação de valores e sentidos. Estaríamos falando de uma geografia pela apreciação e exploração do sabor ligado à paisagem e ao lugar. Significados culturais dão sentido à experiência de preparar e degustar alimentos, sendo a degustação um ato experiencial pelo sentido do paladar.

O sabor da geografia pode conduzir ao entendimento mais estreito homem-lugar e de sua identidade territorial. Devemos reconhecer no sabor uma expressão geográfica, pois assim, se manifesta enquanto valoração de paisagem. O sabor está intimamente ligado à paisagem e ao lugar, transformando-se em gosto ou degustação via paladar.

Os sabores estão entre os símbolos utilizados por discursos identitários para reagir diante da projeção de imagens e de um imaginário ligado à natureza e à cultura, como os processos recentes no Brasil de tombamento de alimentos como bens imateriais: patrimônio cultural.

O turismo, não é de hoje, descobriu a alimentação como atrativo, sendo estas imagens mais ou menos manipuladas, dependendo do contexto. Mas é possível pensar na gastronomia a partir de seus valores culturais, da ligação direta com o lugar e as pessoas, sua tradição. "É preciso resgatar e dar visibilidade às nosssas tradições, ampliando o acesso às informações para o maior número possível de pessoas" (ABRASEL, 2004, p.5).

A geografia procura dar sentido ao sabor enquanto dimensão que busca resgatar e dar visibilidade à memória que se desvela no 
GRATÃO, L.H.B \& MARANDOLA JR., E. Sabor da, na e para Geografia gosto geograficamente vivido, associado a paisagens e lugares. É o que vem sustentar a nossa abordagem: o sabor enquanto sentido e sensação humana de gosto. Sabor e aroma remetem aos costumes e sensações, bases culturais do imaginário das pessoas.

\section{Sabor na Geografia}

A percepção do meio ambiente trouxe para o campo geográfico um importante referencial no tocante aos estudos dos sentidos, especialmente a visão (SAARINEN, 1969; OLIVEIRA, 1977; 2000). Não só no sentido perceptivo, como também do significado simbólico que expressa como percebemos o mundo que nos rodeia.

Sabemos que a percepção do mundo é em grande parte visual. Percebemos e construímos o nosso ambiente com base principalmente na visão, o sentido mais desenvolvido em nossa cultura ocidental, embora as outras percepções (olfativa, auditiva e tátil-cinestésica) sejam igualmente importantes na nossa experiência ambiental. $\mathrm{O}$ nosso mundo não é apenas composto de cores e formas. Enquanto psicologicamente a visão é considerada uma sensação, a percepção é definida como o significado que atribuímos às nossas sensações (OLIVEIRA, 1977). A sensação necessita de órgãos sensoriais para receber os estímulos provenientes do exterior, órgãos estes que possuem estruturas e funções apropriadas para captar os sinais específicos.

A partir dessa abordagem, a Geografia reconduziu os estudos sobre paisagem e lugar, que passaram e ser entendidos também em sua dimensão perceptiva, experiencial e sensorial (COSGROVE e DANIELS, 1988; BERQUE, 1990; ENTRIKIN, 1991; BESSE, 2006). Mais do que percepções individuais, elas puderam ser interpretadas como construções culturais, permeadas de significados, expressando ou representando o processo de construção das identidades (RELPH, 1979; JACKSON, 1989; LE BOSSÉ, 2004). 
GRATÃO, L.H.B \& MARANDOLA JR., E. Sabor da, na e para Geografia

Há um duplo movimento na construção das identidades regionais, paisagens e lugares: a percepção enquanto experiência pessoal e a os valores culturais enquanto produção coletiva. $\mathrm{O}$ primeiro movimento é vivido e significado enquanto o segundo é histórico e imaginário. Assim, as percepções também são culturalmente construídas, permitindo que acompanhemos os dois movimentos.

Um terceiro pólo dessa construção, base da relação homemmeio, é o ambiente. Tanto em seus aspectos materiais quanto em sua projeção imaginária, a natureza compõe essa tríade da experiência ambiental, permitindo que uma investigação por esse campo trace os nexos entre ambiente, cultura e experiência (MACHADO, 2007).

O sabor é um elemento essencial no conhecimento geográfico associado à cultura, à natureza e ao seu imaginário, reclamando uma abordagem focada na valoração da paisagem e do lugar e nas preferências ambientais. Imaginário e memória compõem a expressão essencial dessa geografia, sua geograficidade (DARDEL, 1952), permitindo a busca da identidade regional culturalmente construída.

A percepção geográfica conduz essa abordagem pela interação homem-natureza. Frémont (1980), estudando a região enquanto espaço vivido, aponta a percepção como uma das relações fundamentais entre o homem e o espaço, auxiliando na compreensão da região e os lugares, combinando intimidade e individualidade de cada um no processo coletivo de organização do espaço. Nessa teia de relações, o espaço vivido é uma experiência contínua e deve integrar a dimensão do tempo (o tempo histórico, mas também e, sobretudo, o tempo pessoal), bem como o movimento, que é deslocação no tempo e no espaço. Por definição, o espaço vivido é egocêntrico, centrado no Ego, e mais particularmente no corpo.

Mas temos de constatar que, se o espaço vivido acede às conceptualizações racionais da inteligência, ao raciocínio 
GRATÃO, L.H.B \& MARANDOLA JR., E. Sabor da, na e para Geografia

num espaço cartesiano e euclidiano, também se revela portador de cargas mais obscuras, em que se misturam as escórias do afectivo, do mágico, do imaginário (FRÉMONT, 1980, p. 27).

$\mathrm{Na}$ outra esfera, a paisagem e a região são culturais, conformando e sendo constituídas por fenômenos coletivos, históricos. O sabor, neste sentido, parte da formação do gosto, do costume e da própria gastronomia, construções sociais ligadas à história de um lugar ou região.

O estudo de Jean-Robert Pitte sobre a geografia cultural francesa é exemplar deste forte vínculo entre paisagem, região e gastronomia, base para a experiência do sabor. $\mathrm{O}$ autor mostra o papel do vinho na compreensão das regiões e paisagens francesas, estando profundamente amarrado à história e à própria geografia da França. Pitte (2006) discute as relações entre os temperos, os alimentos e os hábitos da sociedade francesa. A formação do gosto (a dimensão sociocultural) e da experiência de estar à mesa, de uma determinada forma, em determinado contexto, é parte indissociável da tradição culinária, desenvolvida regionalmente e, em alguns casos, localmente.

Gosto e sabor, associados à alimentação ou à experiência gastronômica, são elementos centrais para pensar o sabor na Geografia. O gosto possui uma referência cultural central cujo processo de construção estabelece um nexo inerente entre história, cultura e paisagem. A associação do gosto com uma concepção de modernidade e de civilização está intimamente associada aos hábitos de comer bem e de degustar (MONTEIRO, 2008). Por outro lado, aqueles classificados como "mau-gostos" podem ter processos culturais identitários fortes que se tornam "maus" por serem negados por uma elite que procura outros padrões, em geral mais modernos, associados a uma imagem de sofisticação e modernidade ligada à sede do sistema.

Nestes casos, muitos sabores e gostos, associados às formas ou regiões decadentes economicamente podem ser por muito 
GRATÃO, L.H.B \& MARANDOLA JR., E. Sabor da, na e para Geografia tempo classificadas como de "mau-gosto" até serem redescobertas e exploradas por sistemas turísticos ou de redefinição de identidades regionais, sendo também tomadas por alguns grupos como símbolo de resistência ou de enfrentamento político (GRATÃO, 2009b).

Em vista disso, tanto na percepção (enquanto sentido) quanto na história (enquanto costume), sabor, gosto e paisagem guardam associações inerentes que vão além das técnicas e hábitos de cultivo ou preparo, as quais permeiam o ato de degustar o alimento e envolvem tanto o imaginário quanto a identidade do lugar ou da região.

\section{Sabor para Geografia}

Se queremos trilhar o caminho do sabor da e na geografia, é preciso pensar o sabor para a Geografia. A abordagem epistemológica e metodológica que se propõe aqui busca compreender o sabor a partir de duas grandes vertentes: a experiencial e a cultural. Buscamos a relação das pessoas (individualmente e culturalmente) com a paisagem, projetando a essência do sabor como elemento cultural que faz parte de seu patrimônio natural-cultural, expressando a ligação dos homens aos lugares habitados. Uma relação que funda e reforça a existência e a realidade geográfica em que "l'homme se sente et se sache lié à la Terre comme être appelé à se réaliser en sa condition terrestre." (DARDEL, 1952, p. 46). "Habitar não é a única maneira de nos situarmos. Todos os atos da vida, particularmente os que se repetem, implicam certas localizações de formas, de signos, de valores, de representações, e, por conseguinte criam lugares." (FRÉMONT, 1980, p. 139).

Todo o lugar tem significado. Combinação de elementos, o lugar se visualiza e se integra na paisagem local e regional. Como declara Lowenthal (1997, p. 20):

Assim como a sobrevivência material dos povos do mundo depende da gestão comum do meio ambiente do planeta, 
GRATÃO, L.H.B \& MARANDOLA JR., E. Sabor da, na e para Geografia

seu bem-estar espiritual exige a administração responsável de suas paisagens. Elas são para todos uma fonte de enriquecimento interior - tanto para quem as admira de longe, e talvez nunca chegue a visitá-las, quanto para quem nelas vive e se sente em casa.

O sabor, assim como outros elementos culturais e naturais, é uma das formas de estabelecer esta ligação homem-terra por meio da experiência da paisagem, do lugar e da identidade regional (GRATÃO, 2009a). Esse é o (per)curso teórico-metodológico que buscamos (per)correr para (des)vendar a geografia e a geograficidade dos sabores procurando ampliar os saberes do lugar pelos seus gostos e sabores.

O sabor integra-se assim à gama de interesses da Geografia, como uma maneira de investigar a paisagem a partir do entendimento de que elas vislumbram horizontes de apreensão, sentidos, gestos e gostos transmitindo mensagens que falam, silenciosamente da percepção, da valorização, da busca dos significados inerentes ao ser humano. Por esta perspectiva, o sabor revela a geografia e a geograficidade das pessoas do lugar, enquanto expressão da cultura e da identidade.

O sabor que guarda (e desvela) experiência e memória da paisagem e do lugar, como as imagens, os símbolos, os mitos não é uma invenção psíquica do ser humano, mas uma função de revelar essências do ser. Estuda-lo nos leva a conhecer as ligações existenciais homem-terra, um dos caminhos de investigação geográfica que pressupõe esta pesquisa.

Sabor embala os sonhos, a memória, fonte de inspiração poética, tal como se presencia em outras imagens simbólicas. O sabor é fruto da terra. Está presente no imaginário da natureza e na cultura. A associação natureza/paisagem/tradição se revela como conteúdo material e imaginário. $\mathrm{O}$ ato de comer é identitário e, portanto, revela a identidade. Como os sabores se tornam símbolos de lugares, paisagens e regiões? Como se dá sua inserção na alimentação local? Quais os significados culturais ligados ao seu consumo? Como eles se projetam, contemporaneamente, na 
GRATÃO, L.H.B \& MARANDOLA JR., E. Sabor da, na e para Geografia

promoção e reinvenção de tradições e na construção de novas identidades? Quem são os atores e personagens desse processo?

Se a gastronomia ajudou a criar a civilização, o sabor, enquanto expressão da identidade cultural e da paisagem, é essencial para compreender as tradições culturais. Um caminho que leva à conservação e preservação do meio ambiente, quando considerado enquanto memória da natureza - memória de paisagem.

Desta feita, a relação geografia e sabor nos permite ampliar a compreensão da experiência geográfica do mundo, uma das tarefas que a abordagem cultural em Geografia (CLAVAL, 2001) e a própria Geografia Humanista se propuseram enquanto maneira de incorporar um sentido humanista para a ciência geográfica (MARANDOLA JR., 2005b).

As possibilidades da exploração desta fronteira do conhecimento, no entanto, extrapolam em muito tais abordagens. Incorpora-se como movimento de resistência cultural impressa e expressa na identidade regional, especialmente em áreas de exploração turística, de construção de novas identidades ou resgate de antigas.

Símbolo de resistência (existência) diante da projeção de imagens e de um imaginário ligado à natureza e à cultura, o sabor nos conduz ao enraizamento com a Terra, uma dimensão essencial da geograficidade.

\section{Referências bibliográficas}

ABRASEL - Associação Brasileira de Bares e Restaurantes. Caminhos do Sabor: a estrada real. Belo Horizonte: Gutenberg/ABRASEL, 2004.

BACHELARD, Gaston. A poética do espaço. (trad. Antonio de P. Danesi) São Paulo: Martins Fontes, 1993.

BERQUE, Augustin. Médiance: de milieux em paysages. Paris: Belin, 1990. 
GRATÃO, L.H.B \& MARANDOLA JR., E. Sabor da, na e para Geografia BESSE, Jean-Marc. Ver a terra: seis ensaios sobre a paisagem e a geografia. (trad. Vladimir Bartalini) São Paulo: Perspectiva, 2006.

BLEY, Lineu. Morretes: um estudo de paisagem valorizada. In: DEL RIO, Vicente; OLIVEIRA, Lívia de (orgs.) Percepção ambiental: a experiência brasileira. São Paulo: Studio Nobel, 1996. p.121-138.

CLAVAL, Paul. Épistémologie de la géographie: comprendre le monde tel que les hommes le vivent à travers les paysages, les patrimoines et la confrontation des cultures. Paris: Nathan Université, 2001.

COSGROVE, Denis; DANIELS, Stephen (eds.). The iconography of landscape. Cambridge: Cambridge University Press, 1988.

DARDEL, Eric. L' Homme et La Terre - Nature de la réalité géographique. Paris : Ed. PUF, 1952.

ENTRIKIN, J. Nicholas. The betweenness of place: towards a Geography of Modernity. Baltimore: The Johns Hopkins University Press, 1991.

FRÉMONT, Armand. A Região, Espaço Vivido. (trad. Antonio Gonçalves). Coimbra: Livraria Almedina, 1980.

GRATÃO, Lúcia H. B. Ecologia da Paisagem ao Sabor da Terra. In: SEABRA, Giovani (org.) Educação Ambiental. João Pessoa: UFPB, 2009a. p. 25-38.

- Sabor \& saberes no destino turístico - valoração de paisagem e identidade cultural. In: SEABRA, Giovani; MENDONÇA, Ivo T. (orgs.) IV Simpósio de Turismo Sertanejo: arranjos Produtivos do Turismo. Caruaru: UFPB, 2009b. 
GRATÃO, L.H.B \& MARANDOLA JR., E. Sabor da, na e para Geografia

JACKSON, Peter. Maps of meaning: an introduction to cultural geography. Londres: Routlegde, 1989.

LE BOSSÉ, Mathias. As questões de identidade em Geografia Cultural - algumas concepções contemporâneas. In: CORRÊA, Roberto L. e ROSENDAHL, Zeny (orgs.) Paisagens, textos e identidade. Rio de Janeiro: EdUERJ, 2004. p.157-179.

LÉVI-STRAUSS, Claude. O cru e o cozido. Mitológicas 1. São Paulo: CosacNaify, 2004.

LOWENTHAL, David. Paisagens Culturais. Correio da Unesco, p. 18-20, Nov. 1997.

MACHADO, Lucy M.C.P. Paisagem valorizada: a Serra do Mar como espaço e como lugar. In: DEL RIO, Vicente; OLIVEIRA, Lívia de (orgs.) Percepção ambiental: a experiência brasileira. São Paulo: Studio Nobel, 1996. p.97-120.

. Paisagem cultural. In: KOZEL, Salete; SILVA, Josué C.; GIL FILHO, Sylvio F. (orgs.) Da percepção e cognição à representação: reconstruções teóricas da Geografia Cultural e Humanista. São Paulo: Terceira Margem, 2007. p.139-157.

MARANDOLA JR., Eduardo. Da existência e da experiência: origens de um pensar e de um fazer. Caderno de Geografia, Belo Horizonte, v. 15, n. 24, p. 49-67, 2005 a.

- Humanismo e a Abordagem Cultural em Geografia. Geografia, Rio Claro, v. 30, n. 3, p. 393-420, 2005 b.

MERLEAU-PONTY, Maurice. Fenomenologia da percepção. (trad. Reginaldo di Piero) Rio de Janeiro: Freitas Bastos, 1971. 
GRATÃO, L.H.B \& MARANDOLA JR., E. Sabor da, na e para Geografia MONTANARI, Massimo. Comida como Cultura. São Paulo: Ed. Senac, 2009.

MONTEIRO, Maurício. A construção do gosto. São Paulo: Ateliê Editorial, 2008. 353p.

OLIVEIRA, Lívia de. Contribuição dos estudos cognitivos à percepção geográfica. Geografia, Rio Claro, v.2, n.3, p.61-72, abr. 1977.

. Percepção da paisagem geográfica: Piaget, Gibson e Tuan. Geografia, Rio Claro, v.25, n.2, p.5-22, 2000.

PITTE, Jean-Robert. Géographie culturelle. Paris: Fayard, 2006.

RELPH, Edward C. As bases fenomenológicas da Geografia. Geografia, Rio Claro, v.4, n.7, p.1-25, abr. 1979.

SAARINEN, Thomaz F. Perception of Environment. Washington: AAG, 1969. 37p. [Resource Paper n.5]

TUAN, Yi-Fu. Espaço e Lugar: a perspectiva da experiência. São Paulo: DIFEL, 1983.

Recebido em dezembro 2010 Aceito em junho de 2011 